\title{
Atypically located spider angioma
}

\author{
Atipik lokalizasyonlu spider anjiom
}

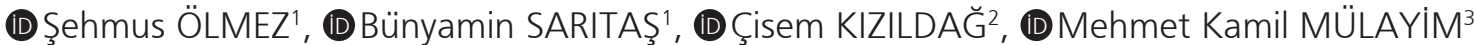

Departments of ${ }^{1}$ Gastroenterology and ${ }^{2}$ Internal Medicine, University of Health Sciences, Adana City Training and Research Hospital, Adana, Turkey

Department of ${ }^{3}$ Dermatology, Kahramanmaraş Sütçü İmam University, School of Medicine, Kahramanmaraş, Turkey

\section{To the Editor,}

A spider angioma or spider naevus is a type of telangiectasis found slightly beneath the skin surface, often containing a central arteriole and many small vessels which radiate outwards like a spider's web. Applying pressure to the center of the lesion leads to fading of the lesion. Spider angioma is a common presentation of liver cirrhosis, especially alcoholic cirrhosis. Spider angiomas are found only in the distribution of the superior vena cava, and are thus commonly found on the face, neck, upper chest and upper arm. Spider angioma is rarely observed on hand $(1,2)$. Here, we report a a very rare case with spider angioma on back of hand.

A 54-year-old male patient admitted to our clinic with icterus and ascites. The patient had a diagnosis of alcoholic liver cirrhosis one month before. On physical examination, he had icterus and ascites. He had spider angiomas on his back, neck and on the back of his right hand, just proximal to second metacarpophalangeal joint (Figure 1). The patient's Child Turcotte Pugh score (CTP) and model for end stage liver disease (MELD) scores were 12 and 22, respectively. Abdomen ultrasound showed cirrhosis with massive ascites. Endoscopy revealed grade 1 esophageal varices and portal hypertensive gastropathy. The patient gave written consent regarding this article.

Spider angioma appears frequently in alcoholic cirrhotic or noncirrhotic alcoholic liver diseases with deuteriation of liver functions. Although, the exact cause of SA is not known, there have been many theories of possible etiologic factors such as disturbance of sex hormones (increased level of luteinizing hormone, decreased level of testosterone and a higher estradiol/testosterone ratio), angiogenesis, vasodilation, alcohol abuse, hyperdynamic circulation state, and liver dysfunction $(3,4)$. The number and size of SA are correlated with the degree of liver disease $(1,3,4)$.

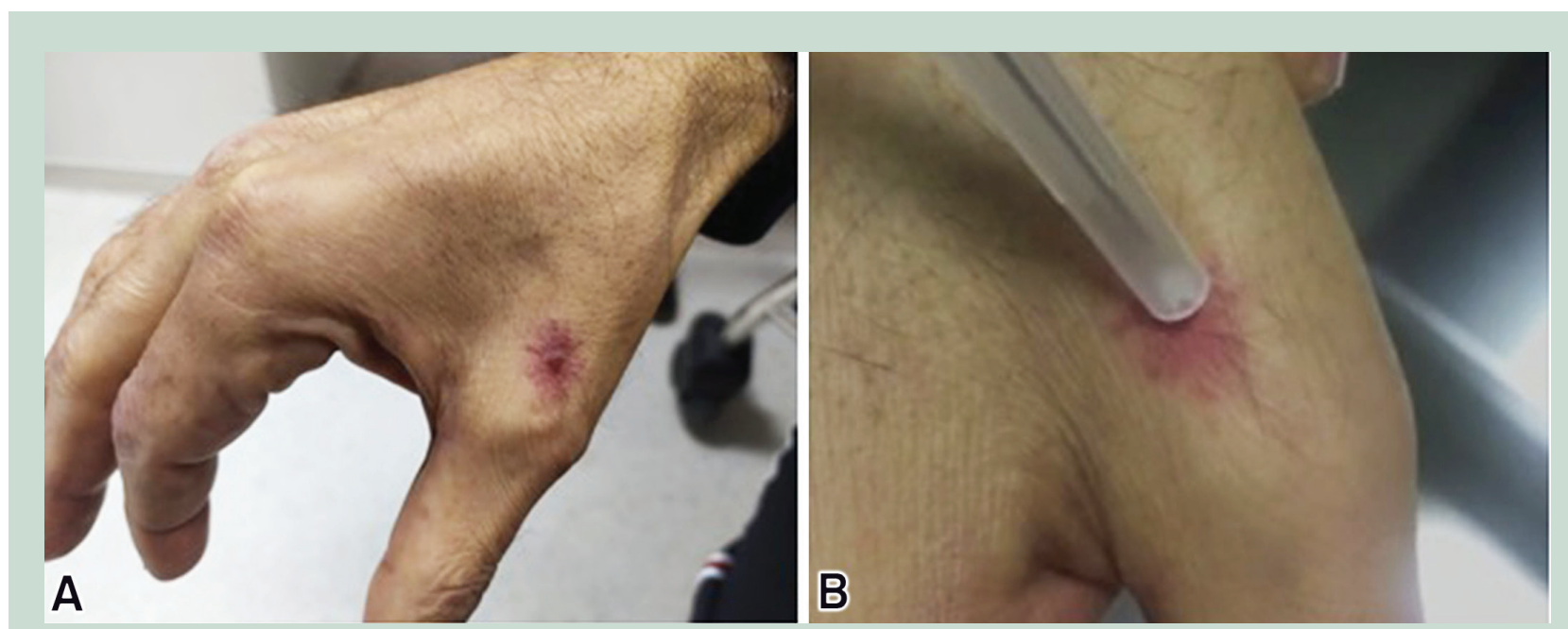

Figure 1. A. Spider angioma on back of right hand, proximal to first metacarpophalangeal joint, center is dark red with dome shape, surrounded with telangiectatic small vessels and erythema. B. Pressing on the center of the lesion, lesion is fading temporarily.

Correspondence: Şehmus ÖLMEZ

Department of Gastroenterology, University of Health Sciences, Adana City Training and Research Hospital, Yüreğir/Adana Phone: +90 3224559000 •E-mail: drsehmusolmez@gmail.com
Ölmez Ş, Sarıtaş B, Kızıldağ Ç, et al. Atypically located spider angioma. The Turkish Journal of Academic Gastroenterology 2021;20:62-63. DOI: 10.17941/ agd.931889

Manuscript received: 02.12.2020 - Accepted: 08.12.2020 
Our patient was a heavy drinker and had alcoholic liver cirrhosis with high CTP and MELD score. Although, our patient had multiple telangiectasias, it is a very rare finding of SA, observed on back of hand.

\section{REFERENCES}

1. Reuben A. Along came a spider. Hepatology 2002;35:735-6.

2. Samant H, Kothadia JP. Spider Angioma. StatPearls. 2020: Treasure Island (FL).

3. Li CP, Lee FY, Hwang SJ, et al. Spider angiomas in patients with liver cirrhosis: role of vascular endothelial growth factor and basic fibroblast growth factor. World J Gastroenterol 2003;9:2832-5.
All of the authors declare no conflict of intererest regarding this article. All of of the authors have no financial interest regarding this article. The study was conducted in accordance with the Declaration of Helsinki Ethical Principles.

4. Sharma V, Aggarwal S, Vadada D. Spiders on the skin: Spider angioma. Journal of Symptoms and Signs 2012;1:15-9. 